\title{
UM OLHAR SOBRE O CURSO DE PEDAGOGIA: PRÁTICAS DOCENTES PREDOMINANTES
}

\author{
A VIEW ON PEDAGOGY COURSE: PREVAILING TEACHING PRACTICES \\ UNA MIRADA AL CURSO DE PEDAGOGÍA: PRÁCTICAS DOCENTES \\ PREDOMINANTES
}

\author{
Tania Mara Zancanaro Pieczkowski \\ Doutora em Educação (UFSM) \\ Universidade Comunitária da Região de Chapecó - UNOCHAPECÓ \\ Chapecó, Santa Catarina - Brasil \\ taniazp@unochapeco.edu.br
}

\begin{abstract}
Resumo: Distintas tendências pedagógicas orientaram práticas docentes em cada tempo histórico, muito embora, mesmo que predominantes, não se apresentem como exclusivas de uma época. O problema de pesquisa que orientou o estudo assim se constitui: As práticas pedagógicas nas aulas do curso de Pedagogia fortalecem o protagonismo estudantil no processo de ensino e aprendizagem? O estudo objetivou identificar quais são os elementos pedagógicos predominantes nas práticas pedagógicas de professores formadores do curso de Pedagogia durante as aulas e como os estudantes avaliam essas metodologias. As materialidades empíricas foram obtidas por meio de questionários, com questões fechadas e abertas, aplicados a estudantes dos períodos finais do curso de Pedagogia e examinados por meio da Análise de Conteúdo. O estudo evidenciou que ensinar não se resume à transmissão de saberes elaborados por outros. É preciso mobilizar o estudante para a elaboração do conhecimento.
\end{abstract}

Palavras-chave: Pedagogia. Práticas docentes. Tendências pedagógicas. Protagonismo estudantil.

Abstract: Different pedagogical tendencies guided teaching practices in each historical time, although, even if prevailing, they do not present themselves as exclusive to a specific time. The research problem that guided the study is: Do the pedagogical practices in the Pedagogy Course classes strengthen the student protagonism in the process of teaching and learning? The study aimed to identify which are the predominant pedagogical elements in the pedagogical practices of teachers who form the Pedagogy Course during classes and how the students evaluate these methodologies. The empirical materialities were obtained through questionnaires with closed-ended and open-ended questions, applied to students of the Sixth $\left(6^{\text {th }}\right)$ and Eighth $\left(8^{\text {th }}\right)$ Semesters of the Pedagogy Course and examined through Content Analysis. The study showed that teaching is not limited to the transmission of knowledge developed by others. It is necessary to mobilize the student for the elaboration of knowledge.

Keywords: Pedagogy. Teaching practices. Pedagogical tendencies. Student protagonism.

Resumen: Diferentes tendencias pedagógicas guiaron las prácticas docentes en cada período histórico, aunque sean predominantes, no se presentan como exclusivas de una época. El problema de investigación que orientó el estudio se constituye así: ¿Las prácticas pedagógicas en las clases del curso de Pedagogía fortalecen el protagonismo del estudiante en el proceso de enseñanza y aprendizaje? El estudio tuvo como objetivo identificar cuáles son los elementos pedagógicos predominantes en las prácticas pedagógicas de los docentes que forman el curso de Pedagogía durante las clases y cómo los estudiantes evalúan estas metodologías. Las materialidades empíricas se obtuvieron a través de cuestionarios, con preguntas cerradas y abiertas, aplicados a los alumnos de los períodos finales del curso de Pedagogía y examinados mediante Análisis de Contenido. El estudio mostró que la docencia no se limita a la transmisión de conocimientos desarrollados por otros. Es necesario movilizar al alumno para que desarrolle conocimientos.

Palabras clave: Pedagogía. Prácticas docentes. Tendencias pedagógicas. Protagonismo estudiantil

Para citar - (ABNT NBR 6023:2018)

PIECZKOWSKI, Tania Mara Zancanaro. Um olhar sobre o curso de pedagogia: práticas docentes predominantes. Eccos - Revista Científica, São Paulo, n. 56, p. 1-16, e8487, jan./mar. 2021. Disponível em: https://doi.org/10.5585/eccos.n56.8487 


\section{Introdução}

Este artigo resulta de um projeto de pesquisa cujo objetivo geral foi analisar as práticas pedagógicas nas aulas do curso de Pedagogia, em uma universidade comunitária localizada no oeste de Santa Catarina ${ }^{1}$. A pergunta que direcionou a pesquisa assim se constitui: As práticas pedagógicas nas aulas do curso de Pedagogia fortalecem o protagonismo estudantil no processo de ensino e aprendizagem? Do problema de pesquisa, derivaram as seguintes perguntas de estudo: Quais são os elementos pedagógicos predominantes nas práticas pedagógicas desenvolvidas por professores formadores do curso de Pedagogia durante as aulas? Como a relação teoria e prática está presente nas aulas do curso de Pedagogia, na percepção dos estudantes? Como os estudantes de Pedagogia avaliam as metodologias dos docentes formadores do curso de Pedagogia? O conjunto das aulas no curso de Pedagogia assegura a construção do perfil de egresso indicado do Projeto Pedagógico do Curso, na percepção dos estudantes?

Apesar da compreensão de que teoria e prática não são dicotomizadas, essa problemática é recorrente, inclusive em diálogos estabelecidos com estudantes egressos do curso de Pedagogia ou narrativas de gestores das redes de educação da região, no sentido de que os estudantes são despreparados para a prática. Essa inquietação mobiliza a instrumentalizar os estudantes para a práxis pedagógica ou para a transposição didática, tão necessária ao exercício da profissão.

Saviani (2007, p. 108) ressalta a relação entre a prática educativa e a teoria, definindoa como uma perspectiva dialética, destacando que "[...] a prática é a razão de ser da teoria, o que significa que a teoria só se constituiu e se desenvolveu em função da prática que opera, ao mesmo tempo, como seu fundamento, finalidade e critério de verdade. A teoria depende, pois, radicalmente da prática”. O autor ainda reforça que “[...] sem a teoria a prática resulta cega, tateante, perdendo sua característica específica de atividade humana” (2007, p. 108).

Para Cunha (1992), a forma como o professor desenvolve a aula pode ou não incentivar a participação do estudante no processo de ensino e aprendizagem. Em suas pesquisas, Cunha identificou habilidades de ensino que os "bons" professores apresentaram e as reuniu em cinco grupos: 1- organização do contexto da aula; 2- incentivo à participação do aluno; 3- trato da matéria de ensino; 4- variação de estímulo e 5- uso da linguagem. A autora

\footnotetext{
${ }^{1}$ Pesquisa financiada pelo Programa de Bolsas Universitárias de Santa Catarina (UNIEDU) com recursos do Artigo 170 da Constituição Estadual e Leis Complementares Estaduais $n^{\circ}$ 281/2005; 296/2005; 420/2008 e 546/2011. Agradeço à estudante de Pedagogia, Mélody Rodrigues Fialho dos Santos, que atuou, em parte do tempo, como bolsista do projeto.
} 
afirma que os bons professores organizam o contexto da aula; explicitam o objetivo do estudo, partindo do pressuposto de que é necessário que o estudante esteja consciente do objeto de sua própria aprendizagem, compreendendo o seu papel nesse processo.

Concordo com Galvão; Câmara e Jordão, no sentido de que

[...] o professor é considerado um ponto essencial no contexto de aprendizagem. Cabe a ele ou a ela coordenar o processo educativo, incluindo estratégias de ensino e de avaliação fundamentadas na metacognição e na autorregulação. Assim, uma das tarefas educativas do professor é a construção de ambientes de aprendizagem profundos (ativos e motivadores), onde é dada ao estudante a oportunidade de aprender a pensar, criticar, raciocinar e questionar certezas, incluindo a metacerteza das verdades garantidas pelo acesso a métodos científicos. Como argumenta Freire (1997), as dúvidas que movimentam a evolução da ciência devem constituir parte fundamental do processo educativo. Assim, é preciso substituir as certezas e saberes preestabelecidos na lógica simplista que constitui a pedagogia de hoje por outra, complexa, que trabalhe com conceitos transversais, abertos para a surpresa e o imprevisto (ASSMANN, 1996). Para isso, é necessário que o professor mude o foco de si para o estudante. (2012, p. 633-634).

Considerando as mudanças nas tendências pedagógicas contemporâneas, são esperados o empenho e o comprometimento dos professores formadores atuantes no curso de Pedagogia com o intuito de desenvolver ações educacionais que contemplem as demandas que serão enfrentadas pelos futuros pedagogos na profissão docente. Esta é uma das discussões centrais no curso. Contudo, esse empenho é reconhecido, é percebido, pelos estudantes? As posturas docentes nas aulas de Pedagogia são consideradas suficientemente adequadas à instrumentalização profissional dos egressos? O conjunto das aulas no curso de Pedagogia assegura a construção do perfil de egresso indicado do Projeto Pedagógico do curso? As práticas docentes contribuem para formar o estudante capaz de atuar em grupos e redes? operar com as tecnologias educacionais? buscar aprimoramento contínuo? demonstrar sólido conhecimento científico, técnico, ético e político? demonstrar criatividade e flexibilidade?, dentre tantas facetas anunciadas como necessárias ao profissional contemporâneo.

\section{Procedimentos metodológicos}

A metodologia de pesquisa é definida por Costa como um caminho a percorrer, um processo de investigação amparado em uma concepção teórica, onde "as ferramentas teóricas são como óculos, lentes, que nos permitem enxergar algumas coisas e não outras" (COSTA, 2007, p. 02). Nesse sentido, a autora salienta que, ao problematizarmos um determinado campo, objeto ou fenômeno, estamos inventando algo novo com as nossas "lentes" e que: 
Pesquisar é um processo de criação e não de mera constatação. A originalidade da pesquisa está na originalidade do olhar. Os objetos não se encontram no mundo à espera de alguém que venha a estudá-los. Para um objeto ser pesquisado é preciso que uma mente inquiridora, munida de um aparato teórico fecundo, problematize algo de forma a constituí-lo em objeto de investigação. $\mathrm{O}$ olhar inventa o objeto e possibilita as interrogações sobre ele (COSTA, 2007, p. 148).

Com relação às práticas pedagógicas de professores universitários, muitas perguntas já foram elaboradas. Mas, ao respondê-las, novas indagações se apresentam.

$\mathrm{O}$ estudo proposto envolveu a aplicação de questionários com questões fechadas e abertas, aplicados a estudantes do curso de Pedagogia, que no segundo semestre de 2017 frequentavam um dos últimos quatro períodos do curso (que é composto por oito períodos e quatro anos). No semestre da pesquisa, atendiam ao critério o sexto e oitavo períodos, pois o quinto e sétimo períodos não estavam sendo ofertados. Para a definição dos sujeitos da pesquisa, foi realizada uma aproximação inicial com a coordenação do curso. Posteriormente, o questionário foi encaminhado aos 42 estudantes matriculados nas turmas indicadas, sendo estes, convidados a participar. Estavam aptos a participar do estudo 22 estudantes do oitavo período e 20 estudantes do sexto período. Do total de estudantes aptos, $26^{2}$ participaram, respondendo o instrumento de pesquisa que indagava acerca de: a) metodologias predominantes no curso; b) avaliação dos estudantes acerca do seu envolvimento/participação durante as aulas; c) percepção do estudante acerca da relação teoria e prática propiciada no curso e em relação à efetividade das metodologias na construção do perfil de egresso previsto no Projeto Pedagógico; d) caracterização de aulas consideradas boas ou ruins; e) atitudes docentes consideradas positivas ou negativas.

Responderam aos questionários 18 estudantes do oitavo período, os quais foram aplicados pela professora pesquisadora, e 8 estudantes do sexto período, aplicados pela coordenadora do curso. A aplicação dos questionários aconteceu durante as aulas, mediante assinatura, pelos estudantes, do Termo de Concordância. O projeto de pesquisa foi aprovado no Comitê de Ética em Pesquisa Envolvendo Seres Humanos, vinculado à universidade onde o estudo foi desenvolvido.

Das alternativas do questionário, 50\% contemplaram opções fechadas e abertas (justificativas à resposta) e 50\% se constituíram de questões abertas.

As materialidades empíricas (respostas aos questionários) foram organizadas em categorias e analisadas com base na Análise de Conteúdo, amparada em Bardin (1977). A Análise de Conteúdo refere-se a um conjunto de instrumentos metodológicos que se aplicam a

${ }^{2}$ Nos percentuais de respostas foram consideradas duas casas decimais, o que justifica que a soma de todas as participações não resulta em exatamente $100 \%$. 
fontes diversificadas. Segundo a autora, trata-se de uma hermenêutica controlada, baseada na dedução: a inferência. Enquanto esforço de interpretação, oscila entre o rigor da objetividade e a fecundidade da subjetividade.

Com o estudo, não há a pretensão de chegar a respostas definitivas e generalizantes. Mas, compreender como acontecem as práticas pedagógicas nas aulas do curso de Pedagogia da universidade pesquisada e se essas práticas fortalecem o protagonismo estudantil no processo de ensino e aprendizagem.

\section{Tendências pedagógicas e suas influências na formação de pedagogos/as}

A história da educação, ao longo da civilização ocidental, se confunde com a própria história da humanidade. De acordo com Saviani, à medida em que o homem procura compreender a educação e intervir nela intencionalmente, "vai se constituindo um saber específico que, desde a paidéia grega, passando por Roma e pela Idade Média chega aos tempos modernos fortemente associado ao termo pedagogia" (SAVIANI, 2007, p. 100).

Distintas tendências pedagógicas orientaram, em cada tempo histórico, práticas docentes, muito embora seja necessário considerar que, mesmo que predominantes, as tendências não se apresentam como exclusivas de uma época no que se refere à organização escolar. Segundo Libâneo, (2006, p. 02):

É necessário esclarecer que as tendências não aparecem em sua forma pura, nem sempre, são mutuamente exclusivas, nem conseguem captar toda a riqueza da prática escolar. São, aliás, as limitações de qualquer tentativa de classificação. De qualquer modo, a classificação e descrição das tendências poderão funcionar como instrumento de análise para o professor avaliar sua prática de sala de aula.

Libâneo (2006) denomina e caracteriza as tendências pedagógicas, reconhecendo a historicidade dos fatos relacionados à educação brasileira, categorizando-as em: Tendências da Pedagogia Liberal: subdivididas em quatro tendências, que são: Tradicional, Renovada Progressista (também conhecida como Movimento da Escola Nova), Renovada não diretiva e a Tecnicista; e Tendências da Pedagogia Progressista: subdivididas em três tendências: Libertária, Libertadora e Crítico-social.

Podemos dizer que a Pedagogia Liberal tem uma postura um tanto neutra em relação às mudanças sociais e econômicas, centrando as ações na transmissão dos conhecimentos, às vezes desvinculados das experiências de vida dos estudantes, e tendo no professor o elemento central da aula. Por considerar a manutenção do status quo, a exclusão escolar é considerada natural, numa sociedade em que o mérito individual é naturalizado. 
Por sua vez, a tendência Progressista tem como sua principal luta as mudanças sociais. Dessa forma, todas as exclusões praticadas pela escola são tensionadas, desnaturalizadas, e o movimento se dá no sentido de promover inclusão. Caracteriza-se, também, no dizer de Libâneo (2006, p. 22), como uma tendência em que a escola "[...] propõe um ensino que valorize a auto-educação (o aluno como sujeito do conhecimento), a experiência direta sobre o meio pela atividade; um ensino centrado no aluno e no grupo".

O Curso de Pedagogia no Brasil foi criado na década de 1930 e regulamentado em 1939 pelo Decreto-Lei n ${ }^{\circ} 1.190$ de 4 de abril de 1939, assinado por Gustavo Capanema. Foi uma época "propícia para manifestação de fatos educacionais circunscritos aos debates sobre a criação das primeiras universidades brasileiras" (BRZEZINSKI, 2012, p. 18). As tendências pedagógicas, os processos de ensinar e aprender, ou seja, a ciência pedagógica, o como ensinar melhor, são objetos de conhecimento do curso de Pedagogia.

O Parecer de homologação das Diretrizes Curriculares Nacionais para a Pedagogia CNE/CP de 2006 (Res. n 1, CNE/CP 15/05/2006), foi publicado no Diário Oficial da União, Brasília, em 16 de maio de 2006, na Seção 1, p. 11. No art. $4^{\circ}$, destaca que:

O curso de Licenciatura em Pedagogia destina-se à formação de professores para exercer funções de magistério na Educação Infantil e nos anos iniciais do Ensino Fundamental, nos cursos de Ensino Médio, na modalidade Normal, de Educação Profissional na área de serviços e apoio escolar e em outras áreas nas quais sejam previstos conhecimentos pedagógicos (BRASIL, 2006).

Para Charlot (2006, p. 12), “A pedagogia não é fundamentalmente um campo de saberes, é um campo de axiologia prática, poderíamos dizer, um campo de valores com os meios de colocá-los em ação, ou um campo de práticas ordenadas para determinados finns." Segundo o autor, "afirmar isso não significa depreciar a pedagogia; é constatar que ela está centrada nas práticas e nos fins, e no elo entre os dois, e não nos saberes (CHARLOT, 2006, p. 12).

Cunha (2006) analisa as práticas pedagógicas no ensino de graduação, apresentando algumas categorias consideradas inovadoras: Conhecimento, Mediação, Protagonismo e Reconfiguração do tempo e espaço de aprendizagem. Destaca que esses eixos podem determinar estratégias e iniciativas de inovações no ensino do professor formador. A autora apresenta a inovação na educação como: 
Conceito de caráter histórico social marcado por uma atitude epistemológica do conhecimento para além das regularidades propostas pela modernidade e caracterizado por experiências que são marcadas por: ruptura com a forma tradicional de ensinar e aprender e/ou com os procedimentos acadêmicos inspirados nos princípios positivistas da ciência moderna; gestão participativa, por meio da qual os sujeitos do processo inovador sejam os protagônicos da experiência; reconfiguração dos saberes, anulando ou diminuindo as dualidades entre saber científico/saber popular, ciência/cultura, educação/trabalho etc.; reorganização da relação teoria/prática, rompendo a dicotomização; e perspectiva orgânica no processo de concepção, desenvolvimento e avaliação da experiência desenvolvida. (CUNHA, 2006, p. 445).

Embora sejam recorrentes, no curso de Pedagogia, os discursos de que: a aula puramente expositiva está "superada"; o estudante deve ser ativo na elaboração do conhecimento; é necessário desenvolver o protagonismo estudantil. Mas, esse movimento é perceptível aos estudantes do curso de Pedagogia? Ser professor é muito mais do que ocupar uma sala de aula e transferir informações a um grupo de estudantes, muitas vezes desmotivados com aulas centradas no professor, mas conduzir os estudantes a um processo crescente de protagonismo e autorregulação. ${ }^{3}$

\section{0 que dizem os estudantes acerca do curso de pedagogia}

\subsection{Metodologias predominantes no curso}

Com relação às metodologias (maneiras de conduzir as aulas) predominantes no curso de Pedagogia investigado, foram dadas aos estudantes três opções, além da possibilidade de justificar a resposta: a) Aulas expositivas, centradas no professor; b) Aulas expositivasdialogadas, em que professor e estudantes participam intensamente; c) Aulas em que os estudantes explicitam o que aprenderam após leituras, pesquisas, intervenções externas e o professor faz a mediação pedagógica.

Dos 26 estudantes respondentes, 24, ou seja, 92,30\% percebem a alternativa b como predominante. Um (1) estudante $(3,84 \%)$ aponta a alternativa c e um (1) estudante $(3,84 \%)$ indica as três alternativas.

Dentre as justificativas relativas à alternativa predominante, destaco:

\footnotetext{
${ }^{3}$ Capacidade do estudante de "autorregular sua aprendizagem, ou seja, monitorar, regular e controlar sua cognição, motivação e comportamento tendo em vista seus objetivos". (SAMPAIO; POLYDORO; ROSÁRIO, 2012, p. 119)
} 
As aulas acontecem de forma onde a interação é mútua entre professor e aluno. As aulas são expositivas, dialogadas com fundamentação teórica trazida em uma aula. Após essas práticas, é realizada uma atividade de pesquisa fazendo com que o conteúdo se torne significativo e o conhecimento mais intenso (Entrevistado 1);

Nesta aula, creio que é a melhor maneira de compreender o conteúdo, pois após uma leitura ou contextos, acontecer o diálogo é fundamental para a aprendizagem. (Entrevistado 4);

Praticamente todas as aulas ocorrem de forma dialogada com mediação pedagógica, conversas e troca de conhecimento (Entrevistado 6);

As aulas, em sua maioria, são dialogadas, onde o professor aborda um determinado assunto e os alunos vão contribuindo. São realizados seminários, provas individuais, trabalhos em grupo, dinâmicas, leitura e interpretação de textos (Entrevistado 9);

As aulas durante o curso foram em maior parte expositivas dialogadas, nas quais temos atuação e participação no processo de ensino aprendizagem. (Entrevistado 12);

A maioria das aulas são expositivas, porém podemos sim participar de maneira efetiva. (Entrevistado 13);

Os professores abrem diálogos com a turma, as dúvidas são sanadas e todos aprendem. (Entrevistado 15).

Os estudantes mencionam as aulas expositivas dialogadas como uma forma importante de aprendizagem, mostrando que elas não estão superadas, como algumas manifestações contemporâneas anunciam. Ao longo da pesquisa, os estudantes ressaltam a importância do diálogo, do debate e da interação, durante as aulas.

\subsection{Avaliação dos estudantes acerca do seu envolvimento/participação durante as aulas}

Para responder a esse tópico, relativo a como o estudante percebe o próprio envolvimento durante as aulas, as alternativas de respostas fechadas foram: a) Passivo, ouvinte do que o professor fala; b) Ativo, construtor do próprio conhecimento e; c) Motivado a fazer buscas adicionais, além do que as aulas propiciam. Dos respondentes, 16, o que equivale a $61,53 \%$ indicaram a alternativa $b$. Sete (7) estudantes $(26,92 \%)$, indicaram a alternativa c; um (1) estudante $(3,84 \%)$ indicou a alternativa a; um (1) estudante $(3,84 \%)$ assinalou as alternativas, a e b, e um (1) estudante (3,84\%) não assinalou nenhuma alternativa.

A resposta preponderante (alternativa b) foi justificada pelos estudantes com distintas falas, dentre as quais destaco: 
Percebo que as aulas são bem dinâmicas, mas que ainda tem docentes que não se preparam, chegam na sala sem uma atividade planejada. (Entrevistado 3);

Me considero ativo, não participando de forma dialogada a não ser quando necessário, mas estou sempre fazendo relações, conexões de forma pensada, guardada. (Entrevistado 7);

Sou mais de ouvir, porém acompanho as falas do professor e contribuo quando acho que devo. (Entrevistado 8);

Durante as aulas, tenho a liberdade para expor minha opinião e debater o assunto com a turma. Temos liberdade e autonomia para fazer pesquisas e compartilhar nossas experiências. (Entrevistado 9);

Algumas aulas poderiam ser mais leves e ter mais práticas e que o professor ouvisse mais o aluno. (Entrevistado 10);

Normalmente participo das aulas, questionando, tirando dúvidas, mas depende do professor, é melhor ficar somente ouvindo pois alguns não aceitam nossas opiniões. Somente a desse professor que tem valor. (Entrevistado 11);

As aulas nas quais o professor demonstra ser aberto a debates e opiniões, a participação dos educandos se torna maior. (Entrevistado 12);

Me sinto uma pessoa que está aprendendo a aprender, construindo meu conhecimento. (Entrevistado 14);

Enquanto o professor vai falando, vou confrontando a minha prática, o que vejo e vivencio, fazendo relação com que ele está falando. (Entrevistado 16);

Em algumas disciplinas nos sentimos alunos passivos. Mas, há professores que nos motivam a querer buscar além do que ele está nos trazendo. (Entrevistado 22);

A maioria dos professores de outra área não nos motiva a pesquisar, porém os professores que são formados em Pedagogia nos incentivam. (Entrevistado 23);

Eu gosto muito do meu curso, e gosto quando o professor instiga a nossa autonomia. (Entrevistado 25).

Algumas falas me provocam a avaliar o conceito de passividade e atividade. Estar em silêncio, ouvindo, é sinônimo de ser passivo? Não necessariamente. Algumas metodologias aparentemente passivas, como uma exposição oral, podem provocar o estudante a estabelecer relações complexas. Contudo, o professor precisa compreender que o que é dito, ou o que lemos, não é compreendido pelo sujeito da aprendizagem da mesma forma.

Vigotski (1989) afirma que a escola deve propiciar atividades que tenham significado e sentido para o aluno, superando o que acontece de forma artificial, não interessante. 
O significado propriamente dito refere-se ao sistema de relações objetivas que se formou no processo de desenvolvimento da palavra, consistindo num núcleo relativamente estável de compreensão da palavra, compartilhado por todas as pessoas que a utilizam. O sentido, por sua vez, refere-se ao significado da palavra para cada indivíduo, composto por relações que dizem respeito ao contexto de uso da palavra e as vivências afetivas do indivíduo. (OLIVEIRA, 1997, p. 50).

Ou seja, o significado possui uma dimensão mais generalizante, social. Enquanto o sentido está relacionado à experiência individual.

Amparada em Larrosa (2002, p. 21), acredito que a boa aula precisa produzir experiência, o que segundo o autor, é "“[...] o que nos passa, o que nos acontece, o que nos toca. Não o que se passa, não o que acontece, ou o que toca. A cada dia se passam muitas coisas, porém, ao mesmo tempo, quase nada nos acontece" (LARROSA, 2002, p. 21).

\subsection{Percepção do estudante acerca da relação teoria e prática propiciada no curso e em relação à efetividade das metodologias na construção do perfil de egresso previsto no Projeto Pedagógico}

Para compreender se os estudantes constatam se a relação teoria e prática é propiciada nas aulas no curso de Pedagogia, puderam, além de dissertar acerca da resposta, registrar uma das seguintes opções: a) A maioria das aulas estabelece essa relação; b) Poucas aulas estabelecem essa relação; ou c) Essa relação não acontece nas aulas.

Vinte estudantes (76,92\%) assinalaram a alternativa a, e seis (6) estudantes $(23,07 \%)$ apontaram a alternativa b. Nenhum aluno indicou a terceira alternativa. A seguir, são destacadas algumas escritas dos estudantes para justificar a escolha preponderante:

No curso, essa relação não é apenas estabelecida no desenvolvimento dos estágios, mas no decorrer das aulas com trabalhos após a mediação da teoria. (Entrevistado 1);

É muito comum os professores fazerem essa relação pois estão nos proporcionando o conhecimento e nos preparando para sermos excelentes profissionais. (Entrevistado 2);

Positivamente as aulas fazem essa relação com as práticas, além do curso proporcionar os estágios que também fazem essa aproximação, o que é muito bom. (Entrevistado 3);

Creio que a teoria e a prática possibilitam maior aprendizagem para o estudante, assim como na maioria das aulas, mesmo que aconteça a teoria em maior parte do tempo, a prática também será feita no momento em que o professor possibilitar um exemplo na sua fala. (Entrevistado 4);

Na grande maioria das aulas ocorre essa relação, sempre havendo interligação do teórico com a prática, auxiliando na reflexão e compreensão. (Entrevistado 6);

Muitas aulas unem a teoria com a prática. Os professores compreendem que é importante e significativo para um melhor aprendizado dos acadêmicos. (Entrevistado 7); 
Como as aulas são com bastante diálogo e troca/construção de conhecimento,-coincide a relação teoria e a prática, pois alguém sempre tem algo para contribuir com fatos de experiências vividos e que se encaixa no conteúdo. (Entrevistado 8);

No momento, podemos dizer que a maioria tem a relação, mas tem algumas disciplinas que não fazem muito sentido para o curso. (Entrevistado 11);

As aulas em grande parte possuem relação entre a teoria e a prática dando mais ênfase aos estágios que contemplam totalmente esse aspecto de forma positiva. (Entrevistado 12);

Sinto em dizer que nem todas fazem essa relação, mas a maioria sim. (Entrevistado 15); Pode-se perceber que em diversas componentes houve essa relação da prática com a teoria, o que facilita nosso entendimento. (Entrevistado 21).

Saviani (2007, p. 102) afirma que "a característica mais saliente da pedagogia pode ser identificada na relação teoria-prática. Entendida como 'teoria da educação' evidencia-se que ela é uma teoria da prática: a teoria da prática educativa”.

Questionado se os estudantes consideram que as metodologias adotadas pelos docentes do curso de Pedagogia asseguram a construção do perfil de egresso previsto no Projeto Pedagógico do Curso, a partir das três alternativas oferecidas aos estudantes: a) Sim; b) Não e c) Não conheço o que o PPC do curso estabelece como perfil de egresso, obtivemos as seguintes respostas: 19 sim, o que equivale a 73,07\%; um (1) não, o que representa 3,84\% e seis (6), equivalente a $23,07 \%$ desconhecem.

De maneira geral, os estudantes que responderam a alternativa preponderante justificaram afirmando que os professores indicam no plano de ensino as habilidades e competências presentes no Projeto Pedagógico do Curso. Dentre a manifestações discentes, destaco:

\footnotetext{
Sim, os professores se preocupam em formar pessoas de acordo com o que está no documento, seguindo padrões éticos. (Entrevistado 7);

Acredito que, em grande parte os componentes curriculares contemplam o perfil, fazendo com que possamos ser melhores profissionais. (Entrevistado 12);

[...] vemos professores na maioria das vezes éticos, que avaliam com rigor, que relacionam prática com teoria. Acho que a (Universidade Pesquisada) possui o melhor curso de Pedagogia da região. (Entrevistado 13).
}

Dentre as boas práticas dos professores do curso, na perspectiva discente, são destacadas: aulas expositivas, interativas, dialogadas; trabalhar textos de linguagem complexa em forma de seminário; trazer objetos da prática para a sala, explicando seu significado e dando sugestões; ouvir os estudantes, questionar como está a aprendizagem e se o aluno compreende o conteúdo; integrar teoria e prática nas aulas; estabelecer uma boa relação com o aluno e não 
fazê-lo sentir-se inferiorizado; ouvir as opiniões dos estudantes; motivar a ir além das aulas no processo de aprender; dialogar com os acadêmicos e sanar dúvidas; usar ferramentas como slides, filmes, internet, saídas a campo, aulas práticas/dinâmicas; compreender que nem todos aprendem da mesma maneira; ser ético; avaliar de modo processual e com rigor.

\subsection{Caracterização de aulas consideradas boas ou ruins}

Instigados para descrever uma aula considerada excelente, os estudantes evidenciaram: leituras para fixar o conteúdo, tornando-o significativo; aprofundamento teórico acompanhado de textos e diálogos; aulas em que o professor não fique o tempo todo apresentando slides ou falando, sem debater o tema; aulas práticas possibilitando maior compreensão do conteúdo a ser trabalhado; interação construtiva entre professor e aluno; sair da aula querendo mais e com o pensamento modificado; trabalhar/estudar sobre determinado assunto após apropriação do mesmo; sair da sala de aula para conhecer algo relacionado ao assunto; estudar o conteúdo teórico e fazer prática sobre o mesmo; quando o tempo passa sem que a turma perceba pois o assunto gerou interesse a ponto de buscar saber mais, de ir à biblioteca em busca de mais conhecimento; uma aula que todos possam se expressar, que incentive o aluno a prestar atenção, a ter interesse; uma aula em que os alunos sejam protagonistas também; quando o material disponibilizado é de qualidade e de bom entendimento; quando o conhecimento é realmente construído, na relação da dimensão pedagógica entre professor e aluno; uma aula em que o estudante possa emitir sua opinião, expor o seu dia a dia, fazendo relação com o tema que está sendo abordado; aula que possibilita aprender sem cansaço.

As aulas consideradas ruins, na perspectiva discente, são assim descritas: somente expositivas ou que tenham textos a serem lidos em sala; aulas confusas, com materiais não adequados e falta de preparo pelo professor; aulas com slides extensos, só o professor falando a noite toda, se tornando cansativo; quando o aluno não entende e o professor continua falando e quando o aluno pergunta o professor responde grosseiramente, "mal educadamente", ou ignora; aulas sem interação professor-aluno; aulas amparadas apenas no datashow, sem exemplos ou paradas para diálogos; aula com professor autoritário que se acha o detentor do saber; quando o professor usa linguagem muito elevada, dificultando o entendimento; quando não houve planejamento e organização por parte do professor; quando os alunos se sentem intimidados para expor sua opinião; quando o professor é arrogante, chato e grosseiro; quando o professor está despreparado ou sem domínio do conteúdo; aulas com diversas turmas e cursos, quantidade excessiva de alunos. 
A grande maioria dos estudantes salientou a aula centrada no professor, quando somente ele fala, como exemplo de aula ruim.

\subsection{Atitudes docentes consideradas positivas ou negativas}

Um dos tópicos do questionário diz respeito às atitudes docentes durante as aulas consideradas positivas pelos estudantes. Dentre as atividades positivas, destacam-se: quando o professor dá oportunidade de compartilhar e trocar ideias; quando o professor sabe ouvir seus alunos, sejam contribuições positivas ou negativas; um professor bem organizado, que se preocupa com seus alunos e rendimento nas notas; professor que disponibiliza materiais diferenciados como: vídeos, brinquedos, atividades lúdicas; ouvir o estudante, aumentar a autoestima discente; flexibilidade, pontualidade, respeito, ser discreto e compreensivo; auxiliar, respeitar, e compreender o aluno; ser flexível, ouvir opiniões; ser descontraído nos momentos certos, não deixando as aulas tensas; organização e respeito; aceitar as colocações dos alunos, ser respeitoso, amoroso em suas maneiras de abordar os conteúdos e falas dos educandos; mostrar-se prestativo para sanar as dúvidas do acadêmico; quando mostra que o estudante não está correto de forma não agressiva e se dispõe a explicar a maneira correta de fazer; diálogo, rigor acadêmico, sem deixar a delicadeza de lado; incentivo, credibilidade na capacidade do acadêmico desenvolver suas tarefas; cobrança do que foi solicitado; cumprimento de horário; compreender que a maioria está cansado, muitas vezes por trabalhar o dia todo; ser flexível à realidade de cada um; ser justo, sem favorecer um mais que o outro; valorizar o esforço do aluno.

As atitudes negativas destacadas pelos estudantes foram: não saber ouvir os alunos; querer "dar nos dedos", não saber ser gentil na forma de explicar o conteúdo; não ser flexível quanto às datas de entrega dos trabalhos; atender ao telefone na sala; ser autoritário, por medo dos alunos; se achar o detentor do saber; não se colocar no lugar do aluno; não ouvir o aluno; faltar com o respeito e ética; negar as colocações dos outros; se achar superior; ignorância, autoritarismo, indisponibilidade perante orientações às dúvidas; desrespeito; reprimir o aluno e não deixar ele se expressar; interromper o estudante nas apresentações, afirmando que ele está errado; não ter compromisso com a aula; desqualificar os conhecimentos e ideias dos alunos; falar muito, sem ouvir os alunos; dar notas sem rigor; indiferença; ameaças; arrogância, desconfiança, não saber colocar-se no lugar do outro; não se preparar adequadamente para a aula; exigir muita coisa; apenas falar sobre o conteúdo, sem ter slides ou algum material impresso; desconsiderar conhecimentos prévios sobre determinados 
assuntos; comer dentro da sala e no meio da explicação; não tratar todos da mesma forma; não valorizar progressos.

Pieczkowski (2019) afirma que “A docência na educação superior é um cenário de intensos desafios, mas mesmo assim, muitos professores universitários assumem a profissão sem uma preparação prévia que lhes possibilite apropriar-se da complexidade dessa seara" (p. 6). Considerando que "O ensino é cada vez menos um processo de transmissão de conhecimentos e cada vez mais um processo de apropriação, de compreensão, de investigação e de descoberta" (PIECZKOWSKI, 2019, p. 7), algumas características docentes são valorizadas pelos estudantes, como: a capacidade de escuta, a mediação, o reconhecimento dos saberes discentes, a criação de ambientes de aprendizagem fecundos que possibilitam o protagonismo estudantil; o rigor acadêmico que não significa rigidez, mas diferente disso, abre espaço para a sensibilidade e empatia, valorizadas pelos sujeitos da pesquisa.

\section{Considerações finais}

É necessária a conscientização de que o/a pedagogo/a não está "pronto" ao concluir o curso, pois o cenário profissional é dinâmico, a trajetória da docência vai se formando na singularidade, na imprevisibilidade, nas possibilidades e impossibilidades dos encontros que o professor estabelece com seus pares. Mesmo assim, o curso deve instrumentalizar os estudantes para a profissão e a eficácia dessa ação depende, em grande parte, da atuação do professor formador: das estratégias pedagógicas adotadas nas aulas; da habilidade de promover inserções nos cenários de prática e de mobilizar os estudantes para a busca do conhecimento.

A pesquisa evidencia que, predominantemente, os estudantes de Pedagogia da universidade pesquisada, estão satisfeitos com o curso, enaltecendo fatores como a atuação dos professores, as metodologias adotadas, a articulação teoria e prática, a oportunização de formação protagônica. Contudo, também há relatos no sentido de professores que centralizam as aulas na forma de exposição, sem o diálogo necessário. Os alunos ressaltam a importância das aulas dialogadas, nas quais os professores oportunizam aos estudantes a exposição de suas percepções e dúvidas, acolhendo os equívocos, os erros e as contradições de uma forma serena e respeitosa.

Concluo que a universidade, por meio do curso de Pedagogia, deve aproximar suas ações às redes de educação básica, compreendendo as demandas e construindo propostas de atuação conjuntas para o fortalecimento dos cenários da prática profissional dos futuros 
pedagogos. Essa forma de trabalhar ampliará a articulação teoria e prática, seguidamente enunciada pelos estudantes como uma necessidade, ora percebida como presente, ora apontada como uma lacuna em alguns componentes curriculares no curso pesquisado.

O estudo evidenciou que a postura pessoal e profissional dos professores é percebida pelos estudantes como relevante para o processo de aprendizagem. Ensinar não se resume em um ato de transmissão de saberes elaborados por outros. É preciso mobilizar o estudante para a elaboração do conhecimento e para a sua profissionalização.

Arrisco dizer que ensinar é produzir experiência, no sentido atribuído por Larrosa (2002, p. 27). O saber da experiência “[...] é um saber particular, subjetivo, relativo, contingente, pessoal. Se a experiência não é o que acontece, mas o que nos acontece, duas pessoas, ainda que enfrentem o mesmo acontecimento, não fazem a mesma experiência".

\section{Referências}

BARDIN, Laurence. Análise de conteúdo. Trad. Luis Antero Reto e Augusto Pinheiro. São Paulo: Martins Fontes, 1977.

BRASIL. Decreto-lei $n^{o} 1.190$, de 4 de abril de 1939. Dá organização à Faculdade Nacional de Filosofia. Diário Oficial da União - Seção 1 de 06/04/1939. Disponível em:

http://www2.camara.leg.br/legin/fed/declei/1930-1939/decreto-lei-1190-4-abril-1939-349241publicacaooriginal-1-pe.html. Acesso em: 19 mar. 2021.

BRASIL. Ministério da Educação. Resolução CNE/CP 1, de 15 de maio de 2006. Diretrizes Curriculares Nacionais para o Curso de Pedagogia, licenciatura. Brasília, 16 de maio de 2006. Disponível em: http://portal.mec.gov.br/cne/arquivos/pdf/rcp01_06.pdf. Acesso em: 19 mar. 2021

BRZEZINSKI. Iria. Pedagogia, Pedagogos e Formação de Professores: busca e movimento. 9. ed. Campinas/SP: Papirus, 2012.

CHARLOT, Bernard. A pesquisa educacional entre conhecimentos, políticas e práticas: especificidades e desafios de uma área de saber. Revista Brasileira de Educação, v. 11 n. 31 jan./abr. 2006. Disponível em: https://www.scielo.br/scielo.php?pid=S1413$24782006000100002 \&$ script $=$ sci_abstract\&tlng=pt

Acesso em: 19 mar. 2021.

COSTA, Marisa Vorraber. Apresentação. In: COSTA, Marisa Vorraber (Org.). Caminhos investigativos II: outros modos de pensar e fazer pesquisa em Educação. 2. ed., Rio de Janeiro: Lamparina, 2007, p. 2.

COSTA, Marisa Vorraber. Uma agenda para jovens pesquisadores. In: COSTA, Marisa Vorraber (Org.). Caminhos investigativos II: outros modos de pensar e fazer pesquisa em Educação. 2. ed., Rio de Janeiro: Lamparina, 2007, p. 139-153. 
CUNHA, Maria Isabel da. O bom professor e sua prática. 2. ed. Campinas, SP: Papirus Editora, 1992.

CUNHA, Maria Isabel. Pedagogia universitária. In: MOROSINI, Marilia Costa. Enciclopédia de Pedagogia Universitária. Glossário. Vol. 2. INEP/RIES: Brasília. p. 445, 2006.

GALVÃO, Afonso; CÂMARA, Jacira; JORDÃO, Michelle. Estratégias de aprendizagem: reflexões sobre universitários. Revista Brasileira de Estudos Pedagógicos, Brasília, v. 93, n. 235, p. 627-644, set./dez. 2012. Disponível em: https://www.scielo.br/scielo.php?pid=S2176$66812012000400006 \&$ script=sci_abstract\&tlng=pt

Acesso: 19 mar. 2021

LARROSA, Jorge Bondía. Notas sobre experiência e saber de experiência. Revista Brasileira de Educação, Rio de Janeiro: Autores Associados, n. 19, jan./abr. 2002. Disponível em: https://www.scielo.br/pdf/rbedu/n19/n19a02.pdf

Acesso em: 19 mar. 2021

LIBÂNEO, José Carlos. Democratização da Escola Pública: A pedagogia crítico-social dos conteúdos. 21. ed., São Paulo: Loyola, 2006.

OLIVEIRA, Marta Kohl de. Vygotsky: aprendizado e desenvolvimento - um processo sóciohistórico. São Paulo: Scipione, 1997.

PIECZKOWSKI, Tania Mara Zancanaro. Mediação pedagógica na relação com universitários com deficiência. Educação Santa Maria, v. 44, 2019 Disponível em:

https://periodicos.ufsm.br/reveducacao

Acesso em: 19 mar. 2021.

SAMPAIO, Rita Karina Nobre; POLYDORO, Soely Aparecida Jorge; ROSÁRIO, Pedro Sales Luís de Fonseca. Autorregulação da aprendizagem e a procrastinação acadêmica em estudantes universitários. Cadernos de Educação. FaE/PPGE/UFPelPelotas, n. 42, p. 119 142, mai./ago. 2012. Disponível em:

https://periodicos.ufpel.edu.br/ojs2/index.php/caduc/article/view/2151

Acesso em: 19 mar. 2021

SAVIANI, Dermeval. Pedagogia: o espaço da educação na universidade. Cadernos de Pesquisa, São Paulo, vol. 37, n. 130. jan./abr. 2007.

VIGOTSKI, Lev Semenovitch. Fundamentos da defectologia: obras completas. Ciudad de La Habana: Pueblo y Educación, 1989. T. V. 